\title{
MEDIAÇÃO E ENSINO DA ARTE: UM EXERCÍCIO DE PARTILHA DO SENSÍVEL
}

\author{
SCHLICHTA, Consuelo Alcioni Borba Duarte - UFPR \\ TEUBER, Mauren - FAP
}

\begin{abstract}
Resumo
Nesse trabalho, pretende-se pensar a educação estética no ensino formal e espaços não escolares partindo do pressuposto de que a produção artística satisfaz a necessidade de expressão de seu criador; porém, enquanto criação para os outros, deve ser compartilhada. Inscreve-se aí o papel do educador em arte: mediador do processo de partilha do sensível ou de apropriação da realidade humano-social também sob a forma de arte. O exercício de mediação - obra, autor, leitores - pode contribuir sobremaneira para tornar visível o significado humano objetivado nas obras de arte. Assim, concebe-se a mediação como um lugar de análise da produção artístico-visual conectando-a as suas condições de produção e apreciação; de produção de novos significados; de distribuição dos bens culturais e, por último, instância de construção de autonomia do aluno na leitura de imagens, processo permanente de significação, de apropriação e de partilha da arte, uma das principais contribuições da educação estética.
\end{abstract}

Palavras-chave: Educação estética. Formação dos sentidos humanos. Leitura de imagens. Mediação. Produção e consumo da arte.

\begin{abstract}
The present work aims at reflecting on the aesthetic education taking into consideration formal teaching as well as environments out of formal school and presupposing that although artistic production aims at meeting its creator needs, it has also to be shared with other people. Thus, the art educator role is to mediate the sharing of sensibility considering not only the production process but also the student as a part of the process that completes and/or changes the work meaning. Therein, the mediation exercise - work, author, readers - may greatly contribute to increase the visibility of the human meaning contained in the art work. A great part of the present study is dedicated to examine mediation as an instrument of artistic-visual production analysis, production of new meanings and distribution of cultural goods. Finally, mediation also builds the student autonomy for reading images thus providing a permanent process of finding meanings as well as appropriating and sharing art, what is one of its main contributions to aesthetic education.
\end{abstract}

Key-words: Aesthetic education; Human sensibility building; Image reading; Mediation; Art Production and Consumption

\footnotetext{
1 Doutora em História pela Universidade Federal do Paraná (2006). Atualmente é professora adjunta da Universidade Federal do Paraná. ${ }^{2}$ Mestre em Educação na linha de pesquisa Cultura, Escola e Ensino da Universidade Federal do Paraná. Atualmente é professora adjunta da Universidade Federal do Paraná.
}

\section{Introdução}


Conforme demonstra a ampliação do número de pesquisas sobre as fronteiras e imbricações existentes entre o legível e o visível, não só a tarefa de se escolher o que e o como ler imagens passou a ocupar um lugar de destaque nas práticas escolares; é crescente também o interesse pelos processos de mediação. Indubitavelmente, assim como a leitura e a releitura de imagens substituíram os famosos exercícios com as técnicas no ensino da arte; a mediação tem sido sistematicamente tratada e defendida como fundamental na educação, em geral, e no processo de aprendizagem da arte, em particular, corroborando tanto para a formação e desenvolvimento do homem quanto na luta pela transformação dessa sociedade capitalista. Sem deixar de pensar, é claro, que a educação corresponde a uma parte da totalidade concreta da sociedade em desenvolvimento, portanto, tem uma relativa autonomia. Desnecessário dizer, dada a obviedade, que "a consciência dos condicionamentos histórico-sociais da educação" (SAVIANI, 1986, p. 66), estende-se à cultura.

Essa perspectiva teórica assume lugar de destaque inclusive no título de nosso texto e é uma clara referência à obra de Jacques Rancière $A$ partilha do sensível: estética e política, publicada em 2005. Cabe esclarecer, ainda, que as reflexões que ora se propõe foram objeto de debate e publicadas nos Anais do $X$ Congresso Nacional de Educação ${ }^{3}$

\footnotetext{
${ }^{3}$ XX Congresso Nacional de Educação e I Seminário Internacional de Representações Sociais, Subjetividade de Educação - SIRSSE, promovidos pelo programa de Pós-Graduação em educação Stricto Sensu, Curso de pedagogia e Centro Acadêmico Paulo Freire, da Pontifícia Universidade Católica do Paraná e pelo Centro Internacional de estudos e Representações Sociais e Subjetividade - Educação (CIERS-ed) da Fundação Carlos Chagas (FCC), realizados no período de 7 a 10 de novembro de 2011. Nessa edição, com o seguinte tema central: "Formação para as mudanças no contexto da educação: políticas, representações sociais e práticas".
} 
E no contexto dessas perspectivas teórico-metodológicas que dedicamos mais atenção ao mediador em arte, problematizando: que prática de leitura, de mediação obra-leitor, tornouse comum nos espaços culturais ou escolares? O que ler nas imagens? Será que o educador em arte sabe sobre o que concentrar seu olhar, sua atenção? Qual sua contribuição como mediador do processo de partilha do sensível, tal como explicitado por Jacques Rancière (1995), ou de apropriação da realidade humano-social também sob a forma de arte? Partindo do título: "Imagem também se lê", publicação de Sandra Ramalho e Oliveira (2009), pode-se argumentar a favor de um trabalho contínuo e sistemático de alfabetização artístico-visual na escola ou a leitura de imagens é um processo que se dá espontaneamente?

Enfim, essas são algumas das problemáticas que têm ocupado lugar nos debates teóricometodológicos suscitados pela leitura de imagens no ensino da arte - leia-se: de acesso à produção artístico-visual - e implicam uma análise mais abrangente sobre as relações: de um lado, entre as posições assimétricas dos sujeitos tendo em vista seus interesses ou "a participação desigual das classes sociais na criação e na recepção artísticas" (CANCLINI, 1984 , p. 3); de outro, partindo do pressuposto de que a produção artística satisfaz a necessidade de expressão de seu criador; porém exige uma nova apropriação que só se efetua no processo do consumo, é necessário pensar as relações entre subjetividade e objetividade, entre produção e consumo, entre os modos de ver e alfabetização visual.

Além disso, concordando com Vázquez (1978, p. 264), há uma estreita relação entre produção e consumo e que a arte é uma práxis criadora duplamente social:

na medida em que, sendo uma criação única, individual e irrepetível, é a criação de
um indivíduo socialmente determinado; e na medida em que a obra de arte não só
satisfaz a necessidade de expressão do seu criador, mas também a de outros,
necessidade que, por sua vez, estes só podem satisfazer quando penetram no
mundo criado pelo artista, compartilhando-o, dialogando com ele. O objeto criado,
por isso, é uma ponte ou instrumento de comunicação.

De fato, sem a apropriação crítica das convenções fixadas em cada modelo social, econômico, político, que determinam quais objetos reúnem qualidades estéticas e quais não, somos incapazes de examinar o conteúdo das representações artísticas, filosóficas, jurídicas, políticas. Porém, esse imaginário só revela seus segredos àqueles que sabem o 
que vêem; que vêem a realidade não como um inocente amontoado caótico de imagens; mas a realidade para si ou para o homem. O que significa que a posse desse imaginário como um sistema de representações, crenças, pensamentos, imagens de mundo requer um aprendizado. Logo, é necessário desnudar um viés, modelado no senso comum, que exerce vigorosa influência sobre o fazer docente na contemporaneidade: a noção generalizada de que é "naturalmente fácil" ler quaisquer imagens.

Por certo, a leitura realizada por um aluno com conhecimento precário dos códigos de construção da imagem é de caráter mais emotivo que cognitivo; porém, não é tarefa fácil evitar esse engodo e ter claro, primeiro, que a sensibilidade estética não é um atributo inato ao sujeito, nem o senso estético uma qualidade natural ao objeto; segundo, que a leitura de imagens enquanto práxis mediada pelo educador em arte requer um campo de conhecimentos interdisciplinares, tanto históricos e antropológicos quanto estéticos, que consubstanciem o ensino-aprendizagem de estratégias de interpretação das imagens.

Iniciemos nossa reflexão, pois, clareando os sentidos do termo "imagem" problematizando: o que a distingue de outros textos? A imagem, assim como um texto escrito, exige uma alfabetização? É "figuração" ou "transfiguração" do real? Uma pintura se reduz a um simples conjunto de formas, linhas, cores? Como representação da legibilidade ou legitimidade a realidade humano-social ou a imagem é apenas um reflexo da realidade? Afinal, o que impulsiona os educadores em arte para o uso da imagem: o valor mais pragmático do exercício de leitura (muitas vezes, apenas de descrição do que se vê) em sala de aula ou o valor epistemológico da mediação, como um meio de compartilhamento da cultura e da arte?

A princípio, argumentamos que a produção e a apreciação da arte só podem ser adequadamente compreendidas dentro de uma perspectiva sociológica; realizam-se num contexto de relação entre quem a produz, sua finalidade humano-social e para quem se destina e seus sentidos pressupõem a interação entre os homens. Cabe, pois, começar construindo um mapa cognitivo para se compreender a imagem: reflexos ou representações da realidade humano-social? 


\section{Imagem: reflexos ou representações da realidade humano-social?}

Uma imagem, segundo Damasceno, "é uma semelhança feita a partir de um modelo com o qual e para o qual difere em algumas coisas, pois certamente não se identifica completamente com o arquétipo" (2004, p. 32).

De um modo geral, pode-se deduzir que as imagens são representações e enquanto sistemas simbólicos são interpretações; porém, se a leitura se mantiver presa a identificação ou descrição do que é dado a ver de imediato na imagem; sobretudo àqueles que carecem dos códigos de sua apreciação; pode não só impedir que o leitor penetre nos seus significados como também velar, obscurecer e dificultar o seu acesso à sua opacidade. É necessário, pois, ao mediador em arte conhecer a imagem, além da sua simples descrição, apreendendo suas duas facetas: a transparência e a opacidade.

Uma imagem representa, torna presente qualquer coisa ausente, é um modo de reapresentação do ausente, esta é a sua transparência e, nesse sentido, sua função é "tornar presente uma ausência" (CHARTIER, 2002, p. 165). Mas, tomando-se sua segunda função: a opacidade, a imagem pode também exibir sua própria presença enquanto imagem. Nesse sentido, a imagem é o representante, o substituto de qualquer coisa que ela não é e que não está presente, como explica Wolff (2005, p. 39): "olho uma fotografia qualquer de De Gaulle. Digo: 'É De Gaulle'. Olho um retrato de Descartes feito por Franz Hals. Digo: 'É Descartes, é efetivamente ele, reconheço seu sorriso e sua altivez'". Seguindo a linha de raciocínio de Wolff, vemos, neste caso, imagem na sua transparência; mas, quando se diz: "É Franz Hals, é realmente ele, reconheço sua maneira e sua desenvoltura"; significa que se vê: Franz Hals, um estilo, um momento da História da Arte. É aí que se entra na opacidade da imagem.

Sobre essa base, ler uma imagem é ao mesmo tempo assimilação da sua transparência (o que se quer mostrar) e da sua opacidade (do que não se vê), conforme exemplo de Wolff (2005, p. 39):

\footnotetext{
A imagem torna Descartes presente para mim, e (genialmente) sua personalidade, aí está a sua transparência; mas o autor dessa presença não pode ser o próprio Descartes, o próprio autor dessa presença está ele mesmo presente na imagem, ou ao menos a imagem reflexivamente remete à sua causa, Franz Hals, seu estilo, sua personalidade, seu caráter, sua época, etc. É isso a opacidade da imagem. E é isso que Ihe dá valor artístico. Como testemunho de Descartes, nós a olhamos em
} 
transparência; como obra de arte, a consideramos em sua opacidade, julgamos o trabalho de Franz Hals.

Portanto, uma representação é uma construção, uma montagem, consequentemente, avançar na leitura da produção artístico-visual implica ir além da sua transparência, indagar seus sentidos. Por isso, é legítimo falar tanto em leitura de um texto quanto em leitura de um quadro; porém, como chama a atenção Marin (2000, p.19), sempre levando "em conta o que, na página escrita ou impressa, transborda a própria leitura graças a elementos e efeitos de visualização ou de iconização que, embora sejam 'marginais', não são de modo algum inocentes". Também, por isso, as atividades de mediação, de apropriação da imagem na sua opacidade, de construção de seus significados, são de extrema importância; pois, conectam-se com a necessidade de homens e mulheres aprenderem a se orientar, encontrar sentidos e pontos de referência que lhes permitam interpretar a realidade humano-social. Sobretudo levando-se em conta que as imagens que a grande maioria tem acesso estão nos livros didáticos e constituem, muitas vezes, a única ou boa parte da produção artística que os jovens e crianças da escola pública têm acesso.

Por consequência, vale reafirmar a importância da atuação do educador em arte, não somente na mediação ou nos exercícios de leitura das obras de arte em sala de aula; mas, sobretudo na construção de um olhar crítico sobre as condições e os processos que sustentam as práticas de produção de sentidos; no entendimento de que as visões de mundo não são desencarnadas assim como os significados da cultura são engendrados no contexto das práticas específicas que os produzem. E mais, se a arte é "um modo de relação dos homens com os objetos, cujas características variam segundo as culturas, os modos de produção e as classes sociais" (CANCLINI, 1984, p. 11), a mediação desempenha um papel decisivo não só no processo de construção do olhar; mas de conhecimento da realidade humano-social.

Sem sombra de dúvida, a apreciação de imagens é uma das principais práticas no âmbito do ensino das Artes Visuais, pois enriquece a compreensão que os alunos têm de si mesmos e do mundo e, concomitantemente, sua experiência. Afinal, trata-se de uma maneira especificamente humana não só de assimilar; também produzir representações fundamentadas na história humana e social. Em verdade, muitas vezes, esquece-se que a imagem também é um discurso por meio do qual alguém tende a impor uma autoridade e legitimar uma visão e como tal carrega conhecimentos e desconhecimentos ao mesmo 
tempo. Por isso, é preciso ver uma imagem na sua complexidade já que, embora aspire à universalidade, o imaginário é marcado pelos interesses daqueles que o produzem.

Desta forma, se as imagens, além de testemunhos, são interpretações, como proceder na leitura dessas representações? Certamente, as formas artísticas de representação não se reduzem a ilustrações de temas ou meras descrições de imagens mentais e são, por sua vez, formas de relembrar uma ausência, de modo que algo ausente é substituído por algo presente que "representa aquele outro"; logo, o exercício de mediação - obra, autor, leitores - pode contribuir sobremaneira para tornar visível o significado humano objetivado nas obras de arte.

Eis o papel que se reivindica para o educador: ser mediador da relação entre os sujeitos e a produção artístico-cultural da humanidade. Mas, afinal, qual a definição de mediação e de mediador?

\section{A mediação como relação}

Mediação, no dicionário Houaiss, significa intervenção, intercessão, interferência ou intermediação; é o ato ou efeito de mediar. Por mediar entende-se o ato de dividir ao meio, ficar entre dois pontos. Etimologicamente, o conceito de mediação pode ser entendido na acepção grega: mésos, como o que está colocado no meio, o ponto médio e o sinal de igualdade entre duas proporções; do radical latim: mediatio como intercessão ou intermédio; o que está entre as duas partes e estabelece uma relação entre elas.

Mediação é uma palavra comum nos dias atuais e usada nas mais diferentes áreas do conhecimento, da filosofia à psicologia. Na filosofia, por exemplo, segundo o dicionário Aurélio, mediação é um "processo pelo qual o pensamento tira uma conclusão, dados os elementos fornecidos pelos sentidos". Já na psicologia, mediação é a "seqüência de elos intermediários (estímulos e respostas) numa cadeia de ações, entre o estímulo inicial e a resposta verbal do final do circuito". No campo educativo, grosso modo, o mediador pode ser considerado aquele que estabelece as condições ideais à ativação do processo de aprendizagem.

A mediação, ainda, tomando como referência a perspectiva marxista, é uma relação que ocorre entre a natureza e o ser humano. Ou seja, o homem projeta sua existência, cria e recria a si mesmo e também a natureza, por meio do trabalho, humaniza-a; enquanto o 
animal submete-se, adapta-se, mantém-se limitado à natureza, que é o imediato. Isto quer dizer que as relações sociais dos e entre os homens só são possíveis por meio de uma atividade, em especial o trabalho, que justamente tem a função de mediatizar homem e natureza.

Marx compreende o modo de produção da sociedade, ou o como a sociedade é constituída por relações materiais entre os homens, por meio, principalmente do trabalho. Essas relações sociais e de produção (que também são sociais) são analisadas numa perspectiva de totalidade, visto que estas relações são constituídas a partir de um contexto econômico, social e político, historicamente determinado. Sendo históricas, evidentemente, não podem ser compreendidas sem seu próprio movimento, que é contraditório e que exige, portanto, conhecer as multideterminações que as constituem, para se aproximar cada vez mais de sua essência e compreendê-las em sua totalidade.

Nessa perspectiva, não só a mediação, mas também as categorias: contradição, totalidade e história são utilizadas. Porém, é importante destacar que funcionam como instrumentos de compreensão do real, como intérpretes que expressam o real correspondendo às condições concretas de tempo e espaço e como sínteses de múltiplas determinações estão em constante movimento. Se isoladas tornam-se abstratas, daí a importância de se considerar o contexto de onde emergem e retornam, continuamente, para explicá-las. O que Marx propõe é conhecer as categorias e a partir delas, por meio do pensamento que vai do abstrato para o concreto, produzir conhecimento.

A mediação, por consequência, é uma categoria histórica e ontológica, do método dialético, que expressa e possibilita as relações sociais entre os homens; é uma abstração, pois é um construto intelectivo que possibilita o pensamento ascender do abstrato para o concreto. Pode-se deduzir, nesse sentido, que a educação (incluindo-se aí a mediação em arte) opera com o mundo histórico-social, visto através de suas múltiplas dimensões, sempre flexíveis e superáveis. A categoria de contradição, assim como a mediação, ocupa um lugar central nessa teoria. Parte da idéia de expressar o real, contraditório como é, buscando nas relações sociais a substância dessa expressão.

Desse modo, a categoria da mediação pode ser entendida:

(...) a partir do momento em que o real não é visto numa divisibilidade de processos em que cada elemento guarde em si mesmo o dinamismo de sua existência, mas numa reciprocidade em que os contrários se relacionem de modo dialético e contraditório. A interação entre os processos permite situar o homem com operador 
sobre a natureza e criador das idéias que representam a própria natureza. Os produtos dessa operação (cultura) tornam-se elementos de mediação nas relações que o homem estabelece com os outros e com o mundo (CURY, 195, p.27-28).

$\mathrm{Na}$ teia de relações contraditórias que se formam da ação educativa, a mediação mostra de modo dialético, momentos diferentes de um todo; permite vislumbrar os fenômenos não isolados e recortados de uma dada realidade, mas a unidade dos contrários, contrários que se relacionam de modo dialético e contraditório. Uma das características da mediação em particular é a que diz respeito a ela expressar uma relação recíproca e indispensável entre as coisas; “... mas [estas coisas] permanecem, entretanto, exteriores entre si” (Marx, 1978, p. 111). Marx apresenta essa idéia ao discutir produção e consumo:

\footnotetext{
A produção não é apenas imediatamente consumo, nem o consumo imediatamente produção; igualmente, a produção não é apenas um meio para o consumo, nem o consumo um fim para a produção, no sentido em que cada um dá ao outro seu objeto, a produção o objeto exterior do consumo, o consumo - o objeto idealizado da produção. De fato, cada um não é apenas imediatamente o outro, nem apenas intermediário do outro: cada um, ao realizar-se, cria o outro.
}

Dessa análise, pode-se deduzir que qualquer modificação no consumo, na produção, na troca ou na distribuição, afetará um ao outro por um ser mediador do outro. Isso significa que o processo de mediação no âmbito da relação ensino-aprendizagem indica que se estabelece na e pela escola, resulta na prática social de alunos e professores em mudança, pois, uma vez transformados e sendo eles parte da sociedade, sua totalidade também é alterada qualitativamente.

O que se propõe, no sentido da mediação dialética, é que o educador em arte reconheça a realidade e as manifestações imediatas de seus alunos (advinda de suas realidades) para, assim, levá-los à superação dessa condição. Isto nos leva a entender que, "a educação, portanto, não transforma de modo direto e imediato e sim de modo indireto e mediato, isto é, agindo sobre os sujeitos da prática" (SAVIANI, 2003, p. 73).

É por isso que, concordando com Canclini (1984, p. 11), não se pode avançar sem se superar os desvios idealistas, sobretudo a explicação metafísica de que o estético é "uma essência de certos objetos" e que à apreciação da arte basta uma atitude de contemplação. Esquece-se que os sentidos humanos 
não podem ser considerados como simplesmente dados pela natureza. O que é especificamente humano, neles, é a criação deles pelo próprio homem. À medida que a natureza se torna humanizada - mostrando as marcas da atividade humana os sentidos, relacionados com os objetos cada vez mais humanamente configurados, tornam-se especificamente humanos e cada vez mais refinados. (MÉSZÁROS, 2006, p. 182).

Esquece-se também que há uma estreita relação entre produção e consumo e que a arte é uma práxis criadora duplamente social:

na medida em que, sendo uma criação única, individual e irrepetível, é a criação de um indivíduo socialmente determinado; e na medida em que a obra de arte não só satisfaz a necessidade de expressão do seu criador, mas também a de outros, necessidade que, por sua vez, estes só podem satisfazer quando penetram no mundo criado pelo artista, compartilhando-o, dialogando com ele. O objeto criado, por isso, é uma ponte ou instrumento de comunicação (VÁZQUEZ, 1978, p.264).

\section{A mediação: categoria constitutiva dos processos psicológicos}

A mediação, partindo da perspectiva sócio-histórica de Vygotsky, é um processo, uma relação que se estabelecesse entre sujeitos construtores de sua aprendizagem; no entanto, concordando com este autor o desenvolvimento depende da aprendizagem, por isso, seu argumento sobre a relevância dos mediadores do conhecimento, nas suas formulações teóricas.

A dimensão social da teoria de Vygotsky, lembrando a formação marxista do psicólogo, concebe que desenvolvimento cognitivo provém do social em direção ao individual, por intermédio da linguagem que, "antes de ser interiorizada, internalizada, é atividade social", ou seja, são as relações sociais que, uma vez internalizadas, determinam a subjetividade, permitindo ao homem constituir-se enquanto membro do gênero humano. Considera-se o elemento central da psicologia vygostskiana - a mediatização - sublinhando a função mediadora da linguagem. Este autor não reduz o conceito de mediação a uma dimensão instrumental. A passagem a seguir esclarece ainda mais esta questão.

Não somente o pensamento é mediatizado exteriormente pelos signos, mas interiormente pelas significações. A comunicação imediata entre as consciências, e 
está aí todo o problema, é impossível não somente psiquicamente, mas também psicologicamente. Não se pode chegar senão por uma via indireta, mediata, isto é, graças à mediatização interna do pensamento antes pelas significações e depois pelas palavras. É porque o pensamento não equivale jamais à significação literal das palavras. A significação serve de mediação entre o pensamento e a expressão verbal, isto é, a via que vai do pensamento à palavra é indireta, interiormente mediata (VYGOTSKY, 1987, p.380).

Isto significa dizer, então, que os processos cognitivos que permitem o funcionamento mental humano são fornecidos pela cultura através da mediação simbólica. Para Vygotsky (1987), o acesso ao objeto é sempre mediado por representações do real e requer dois aspetos complementares: a representação mental que se refere a recortes do real operado pelos sistemas simbólicos de que dispõe o sujeito, e a capacidade de fazer relações mentais na ausência dos referentes concretos, o que equivale a dizer do desenvolvimento da abstração e da generalização. Assim percebe-se uma dupla dimensão da mediação: uma de ordem externa e outra interna, uma dimensão intrínseca ao indivíduo, e a que pressupõe uma mediação de caráter externo. E, assim sendo, a construção do conhecimento procede de uma ação partilhada, que implica um processo de mediação entre sujeitos.

Neste sentido, além de pressuposto teórico-metodológico do processo ensino-aprendizagem da arte, a mediação é o elo entre dois atores, um modo de relação dos alunos, a princípio, com o auxílio do educador ou alunos da mesma idade, com a produção artístico-visual. É o que Vygotsky (1998, p. 97) denomina de zona de desenvolvimento proximal:

\footnotetext{
a distância entre o nível de desenvolvimento real, que se costuma determinar através de solução independente de problemas, e o nível de desenvolvimento potencial, determinado através de solução de problemas sob a direção de um adulto ou em colaboração com companheiros mais capazes.
}

Segundo este conceito, então, um ensino significativo deve preceder o desenvolvimento cognitivo e jamais o contrário. Para Vygotsky, o conceito de aprendizagem mediatizada repousa sobre a hipótese de que a aprendizagem estimula o desenvolvimento.

Partindo da reflexão desse autor, mediação é processo permanente de significação e de apropriação dos instrumentos para conhecer o mundo, no caso do ensino da arte, do 
estético; das relações que os diferentes sujeitos travam com os objetos, artísticos ou não, buscando apreender a quais culturas, modos de produção ou classes sociais pertencem. Mas, dar significado não é simplesmente descrever o que se vê aparentemente em uma imagem, decifrar códigos; é inteirar-se da visão, da perspectiva do outro, acima de tudo, de seus interesses. Por consequência, não cabe mais as abordagens meramente descritivas das imagens, seguidas de exercícios de releitura restritos a cópia das reproduções das obras de arte apresentadas em sala de aula, afinal, a leitura é sempre acompanhada de interpretação.

Nesta perspectiva, qual a contribuição do educador em arte na mediação ou socialização do conhecimento produzido pela humanidade? Como intervir como agente mediador na emancipação dos sentidos dos seus alunos?

\section{A mediação como uma relação entre sujeitos e a arte}

Nessa linha de pensamento a mediação insere: "o fenômeno artístico, o autor, a obra, os difusores e o público" (CANCLINI, 1984, p. 3); incluindo-se neste coletivo o aluno e o educador, é uma relação entre sujeitos e a arte, é principalmente "partilha do sensível", tal como propõe Rancière (1995, p. 7). De acordo com este autor:

\footnotetext{
Partilha significa duas coisas: a participação em um conjunto comum e, inversamente, separação, a distribuição em quinhões. Uma partilha do sensível é, portanto, o modo como se determina no sensível a relação entre um conjunto partilhado e a divisão de partes exclusivas.
}

A partilha, no modo de ver de Rancière, pode ser entendida como repartição ou compartilhamento: fazer a partilha dos bens, uma divisão, uma repartição, das quais se pode tomar um "quinhão" ou compartilhar algo. Em outros termos, implica tanto um "comum" (a cultura, os direitos civis, a liberdade) quanto um lugar de disputas por esse comum; porém, de disputas que, baseadas na diversidade das atividades humanas, definem competências para ver e qualidade para dizer - ou incompetências - para a partilha. A "partilha do sensível" é uma espécie de distribuição de lugares e ocupações, um modo negociado de visibilidade que "faz ver quem pode tomar parte no comum em função daquilo que faz, do tempo e do espaço em que essa atividade se exerce" (RANCIÈRE, 2005, p. 16). 
Além disso, Rancière (2005, p. 17) tende a ver as próprias práticas artísticas como formas modelares de ação e distribuição do comum, uma vez que, segundo ele, elas são "'maneiras de fazer' que intervêm na distribuição geral das maneiras de fazer e nas relações com maneiras de ser e formas de visibilidade".

Que consequências, então, pode-se extrair desta concepção de partilha do sensível para se pensar mediação?

A primeira consequência, conceber a mediação como um lugar de análise da produção artístico-visual conectando-a as suas condições de produção e apreciação, pois, só assim é possível perceber que o autor, o apreciador e os objetos "estão determinados por um sistema de convenções"; por sua vez, também determinados por um modelo de sociedade ou de produção (CANCLINI, 1984, p. 11). A segunda, como um lugar de ação e não de contemplação passiva, de produção de novos significados; terceiro, conceber a mediação como lugar de distribuição dos bens culturais e, por último, como instância de construção de autonomia do aluno na apreciação - leitura e interpretação da sua transparência à sua opacidade - de imagens, como um processo permanente de significação, de apropriação e de partilha da arte.

Enfim, isto significa pensar a apropriação dos sentidos da arte ou do imaginário levando em consideração a produção e seus produtores; pensar os "atributos de instrumentalidade e os estéticos, os traços diferenciais e suas combinações possíveis" (CANCLINI, 1984, p. 11) em sintonia com a finalidade da arte no contexto econômico e cultural em que se insere; o consumo de imagens levando-se em consideração seu contexto histórico específico. Superando-se o viés idealista da apreciação como mera contemplação de coleções de obras; pois, se o consumo é um momento constitutivo da obra, a mediação é o reconhecimento não só do autor, mas também do leitor como sujeito participante, com direito ao seu "quinhão" na partilha dos bens simbólicos; a compartilhar o valor cognoscitivo da arte ou como meio de expressão ou criação de "objetos que o expressam, que falam dele e por ele" (VÁZQUEZ, 1978, p. 69).

Por isso, para avançar além da simples constatação e com base no pressuposto de que a percepção é construída socialmente, é necessário examinar atenciosamente as práticas de 
mediação colocando em xeque a idéia de que a leitura requer uma resposta universal. Evidentemente, as imagens não estão acima das transformações históricas e das diferenças culturais, por conseguinte não podem ser apreciadas como uma linguagem sem fronteiras por sujeitos de qualquer tempo ou classe social. Esquece-se, muitas vezes, que grupos hegemônicos

constroem "representações" do mundo real (isto é, descrições que podem ser codificadas na lei, na literatura, assim como nas imagens) que mantêm os interesses de seu poder ao fazer essas desigualdades parecer "naturais." Dois exemplos poderiam ser: a representação da classe trabalhadora como uma turba perigosa ou como beneficiários agradecidos da riqueza e do valor "aristocráticos"; das mulheres como objetos sexuais idealizados ou como domésticas maternais (FRASCINA, 1998, p. 94).

E, embora tudo leve a crer ao contrário, parece evidente que para apropriar-se desse acervo de bens culturais não basta ao sujeito "elevar-se para receber sua revelação", pois as representações artísticas não são "manifestações superiores, procedentes de uma origem mítica". Assim, é preciso examinar mais detidamente noção de produção e apreciação enquanto práticas de representação mediadas pelas experiências e conhecimentos adquiridos ao longo da vida humana.

\section{A formação dos sentidos humanos: da percepção ingênua a competência artística}

É claro que o processo de criação de objetos humanos é inseparável do processo de formação dos sentidos humanos; no entanto, as primeiras leituras de uma imagem são mais descritivas e fixam-se, por exemplo, na identificação do assunto ou do seu tema, de suas cores, formas, linhas e resultam de uma percepção mais ingênua. Nesse sentido, diferenciase da leitura reflexiva da imagem, que exige do aluno uma "percepção propriamente estética", conforme argumenta Bourdieu (1999, p. 283), uma competência, que passa por um processo educativo de formação dos sentidos, em especial da percepção estética, que 
significados, trata os elementos da representação, folhas ou nuvens, como índices ou sinais investidos de uma função de pura denotação ("é um álamo", "é uma tempestade"), a percepção propriamente estética enfatiza os únicos traços esteticamente pertinentes, a saber, tendo em vista o universo das possibilidades estilísticas os que caracterizam uma maneira particular de tratar as folhas ou as nuvens, isto é, um estilo como modo de representação onde se exprime o modo de percepção, de pensamento e de captação próprio de uma época, de uma classe, de uma fração de classe ou de um agrupamento artístico (grifo do autor).

Ainda na visão deste autor, a percepção estética é uma "aptidão para receber e decifrar as características propriamente estilísticas", uma competência

propriamente artística que se traduz em conhecimento prático (adquirido pelo convívio com as obras ou por intermédio de uma aprendizagem explícita) de sistemas de classificação que permitem situar cada elemento de um universo de representações artísticas em uma classe necessariamente definida em relação à classe complementar (constituída por todas as representações artísticas consciente ou inconscientemente excluídas) (BOURDIEU, 1999, p. 283).

Depreende-se daí que a elevação do nível de sensibilidade em consonância com o processo de iniciação técnica são as facetas integrantes de um mesmo processo de mediação. Ora, ver além da aparência das imagens, de modo a se compreender os modos singulares e históricos de representação da realidade humana e social como sistemas de representação, implica uma redefinição teórica, no mínimo clareza sobre: qual conhecimento é necessário à superação de uma percepção ingênua, que mede a qualidade de uma obra pela sua fidelidade quase fotográfica, como cópia das aparências? Em resumo, como romper com as estratégias de mediação como procedimentos atemporais restritos a forma e descolados do conteúdo inerente a produção artístico-cultural? Assim, tomando-se a imagem como objeto de estudo no educador e/ou mediador em arte que conteúdos são fundamentais de modo a levar os diferentes sujeitos a verem não a coisa em si, mas um estilo?

Nesse sentido, como se enfatizou anteriormente, é fundamental um trabalho continuo e sistemático com as noções de transparência e opacidade, com os conteúdos e estratégias de interpretação, de apreciação das representações artísticas. Ou seja, por meio da apreciação da produção artístico-visual, possibilitar a maioria um olhar sobre si e assim 
compreender-se e aos outros, como seres únicos, isto é, que sua maior singularidade é o que o torna, com toda sua espécie, um ser humano.

É nessa perspectiva que se entende que a arte não se reduz a ornamento, a simples objeto cujo fim é embelezar as paredes das salas ou receituário técnico. Tem sentido, então, um trabalho contínuo e sistemático com os conhecimentos artísticos necessários à compreensão dos sentidos de uma imagem, enfim, é preciso ensinar a ver tanto o conteúdo quanto a forma das representações, artísticas ou não.

\section{Considerações finais}

Conclui-se, então, que as práticas de mediação são de extrema importância, especialmente no âmbito dos espaços escolares ou culturais; pois, de um lado, conectam-se com a necessidade de se oferecer alternativas aos alunos para que aprendam a orientar-se e a encontrar sentidos e pontos de referência, que lhes permitam apreender as imagens para além da sua transparência; de outro, apreender a realidade humano-social para além do que os olhos podem ver.

Os processos de mediação podem, no entanto, ser instrumentos de superação ou reprodução das relações de dominação, ocultando, muitas vezes, que "as formas simbólicas servem para estabelecer e sustentar relações de dominação nos contextos sociais em que elas são produzidas, transmitidas e recebidas" (THOMPSON, 1995, p. 18). Não se pode esquecer que as imagens não são neutras e enquanto representações estão impregnadas de idéias que refletem estruturas sociais, contribuindo para que os seres humanos aceitem ou neguem as visões estereotipadas sobre a realidade e sobre si mesmos. Isso, no entanto, não é apenas tarefa do educador em arte, saber para ver, para compreender os sentidos ou as razões de ser um objeto é meta da educação. Os processos de mediação em espaços escolares ou culturais, longe de exercícios de mera assimilação do repertório de alguém, exigem do mediador-apreciador: um acervo, um conjunto de saberes e um esforço de interpretação da produção artístico-cultural, para vê-la como a expressão de alguém e para outro alguém e como uma mensagem a ser compreendida.

Daí decorre que mediação é construção de olhares, pois, o sentido da arte só existe para aquele que desenvolveu a percepção, as formas de apreciação dos objetos artísticos, as maneiras requeridas pela produção sociocultural. No entanto, não se pode negar, ainda que parte da mesma totalidade, a grande maioria dos estudos no campo da arte tem 
considerado a obra de arte do ângulo do seu criador e relegado as práticas de mediação a uma posição secundária.

Nosso argumento-chave é que a maioria por limites sócio-lógicos (e não individuais) não tem acesso aos códigos de apreciação e produção artísticas. Vista sob essa ótica, a familiarização cultural é uma das finalidades da arte na escola e requer uma iniciação artística teórica e prática, afinal, o talento, o dom, incluindo-se também a criatividade nesse rol, não são em absoluto naturais, ou seja, inatos, mas, podem ser formados; pois se constituem em "produto de origem cultural" (PORCHER, 1982, p.14).

Daí a importância, de um lado, da escola e do educador em arte como mediador da relação entre o aluno e o conhecimento artístico necessário a leitura não só das imagens, mas também da realidade, da sua matriz econômica e política, do seu modelo educacional; do vocabulário corrente, dos erros de perspectiva, dos pontos de vista; de outro, do mediador no museu. Não se pode esquecer que nada substitui o contato direto com as obras, sempre que possível; na verdade, tanto quanto possível, deve-se aliar o conhecimento dos códigos com a apreciação da arte e da cultura in loco. Parece-nos particularmente relevante o acesso aos acervos dos espaços museológicos e que todo homem, mulher, jovem, criança ingressem no mundo da arte e que tomem posse, afinal, por direito, se a produção artística é patrimônio cultural da humanidade, já lhe pertence. É claro que não há garantia de sucesso, mas a tarefa diz respeito a cada um de nós: defender e participar efetivamente na redistribuição da produção artístico-cultural, na partilha do sensível.

\section{Referências Bibliográficas:}

BOURDIEU, P. A Economia das Trocas Simbólicas. 5 ed. São Paulo: Perspectiva, 1999.

CANCLINI, N. G. A socialização da arte - teoria e prática na América Latina. 2 ed. São Paulo: Cultrix, 1984.

CHARTIER, Roger. A beira da falésia: a história entre certezas e inquietude. Porto Alegre: Universidade, 2002.

CURY, C.J. Educação e Contradição: elementos metodológicos para uma teoria crítica do fenômeno educativo. São Paulo: Cortez, 1985, p.27-28 
DAMASCENO, J. Discurso apologético contra os que rejeitam as imagens sagradas. In: LICHTENSTEIN, J. (Org.). A pintura: Textos essenciais. Vol. 2: A teologia da imagem e o estatuto da pintura. São Paulo: Ed. 34, 2004.

FRASCINA, Francis et al. Modernidade e modernismo: a pintura francesa no século XIX. Trad. Tomás Rosa Bueno. São Paulo: Cosac \& Naify, 1998.

GARB, Tamar et al. Modernidade e modernismo. A pintura francesa no século XIX. São Paulo: Cosac \& Naify, 1998.

HOUAISS, Antônio; VILLAR, Mauro de Salles. Dicionário Houaiss da Língua Portuguesa. Rio de Janeiro: Objetiva, 2001.

KLEIN, L. R. Alfabetização: quem tem medo de ensinar? São Paulo: Cortez; Campo Grande: Ed. Universidade Federal de Mato Grosso do Sul, 1996.

MARIN, Louis. Sublime Poussin. Trad. Mary Amazonas Leite de Barros. São Paulo: Edusp, 2000.

MARX, K. (1857) Introdução para a crítica da economia política. São Paulo: Abril Cultural, 1978. Os Pensadores.

MÉSZÁROS, István. A teoria da alienação em Marx. São Paulo: Boitempo, 2006.

PORCHER, Louis (Org.). Educação artística: luxo ou necessidade? São Paulo: Summus, 1982.

RAMALHO E OLIVEIRA, Sandra. Imagem também se lê. São Paulo: Edições Rosari, 2009. RANCIÈRE, Jacques. A partilha do sensível: estética e política. São Paulo: Editora 34, 2005.

RANCIÈRE, Jacques. Políticas da escrita. São Paulo: Editora 34, 1995. 
SAVIANI, D. Escola e Democracia: teorias da educação, curvatura da vara, onze teses sobre a educação política. Campinas/SP: Autores Associados, 36ª ed., 2003.

THOMPSON, John. B. Ideologia e cultura moderna: teoria social crítica na era dos meios de comunicação de massa. Trad. Grupos de Estudos sobre Ideologia, Comunicação e Representações Sociais da Pós-graduação do Instituto de Psicologia da PUCRS: Carmem Grisci, Jefferson Bernardes, Marcos de O. Müller, Rosana Nora, P. Valério Maia, sob responsabilidade do Prof. Pedrinho A. Guareschi. Rio de Janeiro: Vozes, 1995. VÁZQUEZ, Adolfo Sanchez. As ideias estéticas de Marx. 2. ed. Rio de Janeiro: Paz e Terra, 1978.

VYGOTSKY, L. Pensamento e Linguagem. São Paulo: Martim Fonte, 1987.

WOLLF, Francis. O poder da imagem. In: NOVAES, Adauto (org.) Muito além do espetáculo. São Paulo 